\title{
BMJ Open Effects of introduction of an inflammatory bowel disease nurse position on healthcare use
}

\author{
Christine Martinez-Vinson (D) , Sebastien Le, Audrey Blachier, Maud Lipari, \\ Jean-Pierre Hugot, Jerome Viala
}

To cite: Martinez-Vinson C, Le S, Blachier A, et al. Effects of introduction of an inflammatory bowel disease nurse position on healthcare use. BMJ Open 2020;10:e036929. doi:10.1136/ bmjopen-2020-036929

- Prepublication history for this paper is available online To view these files, please visit the journal online (http://dx.doi. org/10.1136/bmjopen-2020 036929).

Received 14 January 2020 Revised 07 April 2020 Accepted 17 April 2020

\section{Check for updates}

\section{(c) Author(s) (or their} employer(s)) 2020. Re-use permitted under CC BY-NC. No commercial re-use. See rights and permissions. Published by BMJ.

Service de Gastroentérologie et Nutrition pédiatriques, Hopital Universitaire Robert-Debre, Paris, Paris, France

Correspondence to Dr Christine Martinez-Vinson; christine.martinez-vinson@ aphp.fr

\section{ABSTRACT}

Objective Inflammatory bowel diseases (IBDs) are chronic relapsing remitting diseases which potentially result in hospitalisation, requiring long-term outpatient follow-up, ideally by a dedicated, multidisciplinary team. In this team, the IBD nurse is the key point of access for education, advice and support.

The aim of this study was to assess the impact of introduction of an IBD nurse position on healthcare use and costs in a tertiary IBD centre.

Methods An IBD nurse was instituted in September 2017 in our multidisciplinary IBD team. We compared differences in healthcare use 1 year before and 1 year after the introduction of an IBD nurse position for all the patients with a confirmed diagnosis of IBD attending the Robert Debre Hospital via two information sources: Programme de Médicalisation des Systèmes d'Information and Centre des Maladies Rares.

Results 252 patients (78.5\% of patients with IBD followed up in our centre) were included in the patient education programme. After the introduction of an IBD nurse position, fewer patients were hospitalised for a flare, with less hospital stays: 56 before vs 28 after $(p=0.002)$. An estimated saving of $€ 35070$ was achieved through the decrease of hospitalisations for flare.

More patients were also hospitalised for diagnosis: 32 hospitalisations before vs 54 hospitalisations after $(p=0.001)$. All other hospitalisation categories were comparable, and the same reasons for hospitalisation were found before and after.

Conclusion This study demonstrates that the IBD nurse position reduces hospital admissions. Instead of the traditional model, the IBD nurse provides accessible advice and allows patients to be outpatients.

\section{INTRODUCTION}

Inflammatory bowel diseases (IBD) are chronic relapsing remitting diseases which potentially result in hospitalisation, requiring long-term outpatient follow-up, ideally by a dedicated, multidisciplinary team. In this team, the IBD nurse is the key point of access for education, advice and support.

IBD produces high costs in health systems. In an inception cohort of 1321 patients in eight European countries and Israel over 10 years, the mean cost of healthcare was

\section{Strengths and limitations of this study}

Design strengths included comparing hospitalisations 1 year before and 1 year after the introduction of an inflammatory bowel disease (IBD) nurse position.

- The extraction of patients with IBD with two information systems allowed exhaustiveness.

- The major limitation was that costs were only attributed to the reduction of hospitalisation.

$€ 1871 /$ patient-year for IBD, $€ 1524 /$ patientyear for ulcerative colitis (UC) and €2548/ patient-year for Crohn's disease (CD). The most expensive resources were medical and surgical hospitalisations, together accounting for $63 \%$ of the cost in $\mathrm{CD}$ and $45 \%$ in UC. ${ }^{1}$ Patients with IBD have significantly greater inpatient healthcare use and costs than agematched and gender-matched hospitalised controls. Over 15 months, a cohort of 102 admitted patients with IBD were acquired and compared with five admitted, agematched and gender-matched controls at a single tertiary centre (510 controls). Patients with IBD had more readmissions (mean 1.72 vs $1.55, \mathrm{p}=0.002$ ) and longer total cumulative length of stay (median 6.8 vs 3.4 days, $\mathrm{p}<0.0001)$ than controls. Median cumulative cost of inpatient healthcare was also higher in IBD compared with controls (\$7052 vs $\$ 5470) .{ }^{2}$ After introducing an IBD service, the healthcare use and disease burden decreased significantly: the number of admissions was lower in patients with IBD than in controls (mean $1.53 \pm 1.03$ vs $2.54 \pm 2.35, \mathrm{p}<0.0001$ ), the mean total cost of inpatient care was lower for patients with IBD than controls (US\$12857.48 (US\$15 236.79) vs US\$30467.78 (US\$53 $760.20), \mathrm{p}=0.005)$. These data suggest that proactive management improved outcomes. ${ }^{3}$

Recently, the first N-ECCO Consensus Statements supported contemporary IBD nursing practice. ${ }^{4}$ The IBD nurse assessed 
understanding of disease by patients and families, provided education to patients with IBD and their parents based on individual needs, aiming to empower the patient to live well with IBD.

Patients report satisfaction of care with the IBD nurse in the team. Some studies have reported the positive effect and value of dedicated IBD nurses on outcomes ${ }^{5-7}$ Unfortunately, these studies showed some important methodological limitations reported in two review articles. ${ }^{89}$ One randomised controlled trial of 100 patients with IBD receiving a specialist nurse delivered counselling package $(n=50)$ or routine outpatient clinic follow-up $(n=50)$, with assessments at entry and at 6 and 12 months, was of low methodological quality: disease remission, patient compliance, clinical improvement, use of nurse-led services, patient satisfaction, hospital admission, outpatient attendance, progression to surgery, length of hospital stay and cost-effectiveness data were not reported. ${ }^{8}$ These studies highlighted the need for higher-quality trials of gastroenterology and IBD specialist nursing interventions to assess the impact of specialist nursing interventions on the care and management of patients with IBD.

Introducing an IBD nurse position could provide sustained direct cost reductions to healthcare by reducing hospital attendance. ${ }^{1011}$

The aim of this study was to assess the effects of introduction of an IBD nurse position on healthcare use and costs.

\section{METHODS}

\section{Role of the IBD nurse}

An IBD nurse was instituted in September 2017 in our tertiary paediatric IBD centre. After having 8 years of experience in IBD (through the gastroenterology department and the IBD day hospital), she followed several advanced courses in patients with IBD management and underwent training to develop an empathetic and active listening role. A dedicated telephone line and email were established for direct access to the IBD nurse. She was accessible every working day, during working hours.

The IBD nurse was present at the initial announcement of the diagnosis to support patients (figure 1). Information brochures and booklets were designed on the basis of frequently asked questions to prevent common uncertainties and to facilitate IBD centre contact information with newly diagnosed patients and were given to children and parents at this time. She further reviewed the patient and parents in a face-to-face appointment during the week following the initial announcement to ensure the diagnosis has been understood.

The IBD nurse was the constant source of contact and provided immediate advice, facilitating the access to the IBD team via telephone or email and rapid access in the event of a flare-up.

The IBD nurse conducted regular patient reviews faceto-face in order to assess understanding and to provide education to patients with IBD and their parents based on

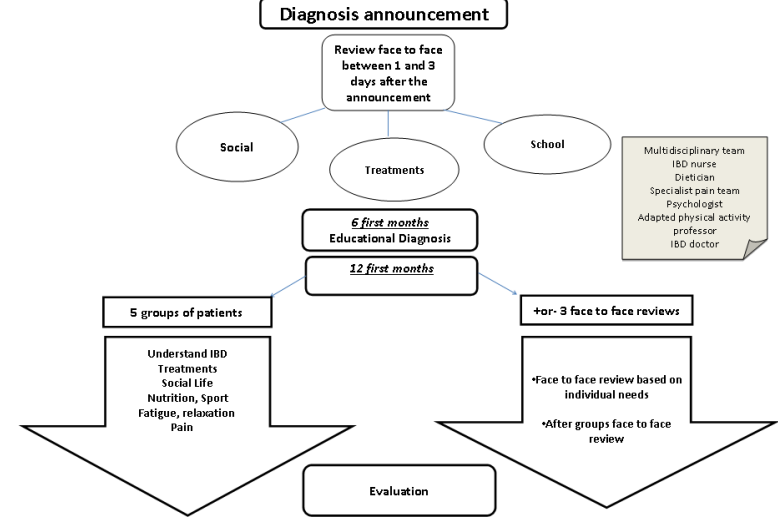

Figure 1 Patient pathway IBD nurse actions from diagnosis announcement to patient education programme. IBD, inflammatory bowel disease.

individual needs, aiming to empower the patient to live well with IBD, as necessary.

Monthly, groups of patients were gathered according to the education programme. The programme was delivered by an IBD education team, including the IBD nurse, an IBD doctor and, if necessary, a specialist dietician, a specialist pain team, or the psychologist or the adapted physical activity professor. The main themes of these meetings were knowledge of the disease and of the treatments, nutrition, fatigue, pain, sports and relaxation. Educational modalities were different according to the age of the patients (groups aged less than 13 years old and groups aged more than 13 years old). Parents were separated from their children and received a specific programme for knowledge of the disease and of the treatments. For the other topics, parents and children were together.

\section{Patients with IBD}

All patients with a confirmed diagnosis of IBD, under 18 years of age and attending the Robert Debre Hospital, whatever the reason or the hospitalisation department for hospitalisation, were identified from October 2016 to September 2018. Patients were collected using the medicoadministrative database Programme de Médicalisation des Systèmes d'Information (PMSI) and the national IBD register Centre des Maladies Rares (CEMARA). ${ }^{12}$ The extraction with these two information systems allowed exhaustiveness. We compared hospitalisations, emergency department visits, day hospital stays, and gastroenterologist consultations before and after the creation of a nurse position.

Characteristics recorded for every patient were extracted from these databases: sex, age, diagnosis (CD or UC), immunosuppressive therapy and biological therapies.

\section{Assessment of cost savings}

The estimated cost of hospitalisations was obtained from the hospital financial department that produced benchmark information. 


\begin{tabular}{|c|c|}
\hline \multicolumn{2}{|l|}{ Characteristics } \\
\hline Educated patients, n (\%) & 252 \\
\hline Crohn's disease & $219(87)$ \\
\hline Ulcerative colitis & $33(13)$ \\
\hline \multicolumn{2}{|l|}{ Gender, n (\%) } \\
\hline Male & $141(56)$ \\
\hline Female & $111(44)$ \\
\hline Age (years), median (IQR) & $15(12-17)$ \\
\hline \multicolumn{2}{|l|}{ Recently diagnosed (<1 year), n (\%) } \\
\hline Yes & $95(38)$ \\
\hline Harvey Bradshaw, median (min, max) & $10(1,14)$ \\
\hline PUCAI, median (min, max) & $35(0,60)$ \\
\hline No & $157(62)$ \\
\hline Harvey Bradsahw, median (min, max) & $0(0,10)$ \\
\hline PUCAI, median (min, max) & $10(0,25)$ \\
\hline \multicolumn{2}{|l|}{ Immunosupressive therapy only, n (\%) } \\
\hline Yes & $90(36)$ \\
\hline No & $162(64)$ \\
\hline \multicolumn{2}{|l|}{ Biological therapy, n (\%) } \\
\hline Yes & $152(60)$ \\
\hline No & $100(40)$ \\
\hline
\end{tabular}

PUCAI, Pediatric Ulcerative Colitis Activity Index.

\section{Statistical analysis}

Categorical variables were described as frequencies and per cents and were compared with $\chi^{2}$ test. A two-sided $\mathrm{p}$ value of $<0.05$ was considered as significant. Statistical analyses were performed using SAS analysis statistical software V.9.4.

\section{Patient involvement}

As this is a health monitoring study using PMSI data, patients were not directly involved. However, the study could be of interest to patients, and we will provide summaries of the research.

\section{RESULTS}

\section{IBD nurse activity}

Between 1 October 2017 and 30 September 2018, 252 patients $(78.5 \%$ of patients with IBD followed up in our centre) were included in the patient education programme ( $56 \%$ boys, median age of 15 years). The characteristics of the educated patients are shown in table 1 . The median age of the patients who received the educational programme was 15 (IQR 12-17, min 6, max 18).

The IBD nurse conducted 565 face-to-face reviews (mean of 2.2 per patient), essentially at the day-hospital $(\mathrm{n}=391)$. Only 29 patients (9\% of patients with IBD) who were expected for patient education did not fulfil their
Table 2 IBD nurse activity

\begin{tabular}{|c|c|}
\hline IBD nurse activity & $\begin{array}{l}\text { Oct } \\
\text { 2017- } \\
\text { Sept } \\
2018\end{array}$ \\
\hline $\begin{array}{l}\text { Active file of patients included in the therapeutic } \\
\text { patient education programme }\end{array}$ & 252 \\
\hline Face-to-face reviews, $\mathrm{n}$ & 565 \\
\hline Face-to-face reviews in consultation & 43 \\
\hline Face-to-face reviews in hospitalisation & 131 \\
\hline Face-to-face review in day hospital & 391 \\
\hline Group of patients, $n$ & 38 \\
\hline Average number of patients in the groups & 5.8 \\
\hline Caregivers also included in the programme & 252 \\
\hline $\begin{array}{l}\text { Number of meetings of the IBD therapeutic patient } \\
\text { education team }\end{array}$ & 39 \\
\hline Number of patients expected but did not come & 29 \\
\hline
\end{tabular}

appointment. Characteristics of the IBD nurse interventions are shown in table 2.

The patients with IBD education team (IBD doctor, IBD nurse, psychologist, dietician at least and sometimes added by the specialist pain team, and the adapted physical activity professor) have met 39 times to organise or share concerns about patients.

\section{Healthcare use}

After the introduction of patients with IBD education programme, fewer patients were hospitalised for a flare (figure 2): 33 patients (12\% of patients with IBD) before introduction vs 22 patients $(6.85 \%$ of patients with IBD) after $(\mathrm{p}=0.016)$, and the number of hospitalisations for a flare was reduced ( 56 before vs 28 after, $\mathrm{p}=0.002$ ).

More patients were hospitalised for diagnosis (IBD suspicion and hospitalisation programmed with colonoscopy and biopsies): 32 hospitalisations before vs 54 hospitalisations after $(\mathrm{p}=0.001)$.

All other hospitalisation categories were comparable. The same reasons for hospitalisation were found before and after, with no statistical difference. Reasons found for hospitalisation were IBD diagnosis, IBD flare, planned

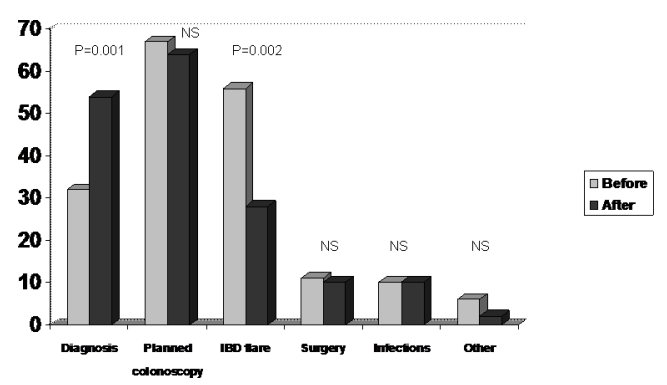

Figure 2 Number of hospitalisations (and reason why) before and after the introduction of an IBD nurse. IBD, inflammatory bowel disease 
colonoscopy, surgery, infection and other (treatment introduction, electrolyte imbalance and pancreatitis).

We also compared (before vs after the intervention of the IBD nurse) the number of patients followed up for IBD in our centre (259 vs 321), day hospital stays (1040 vs $1143, \mathrm{p}=0.2$ ), emergency department visits (152 vs 147 , $\mathrm{p}=0.08$ ) and gastroenterologist consultation (473 vs 531 , $\mathrm{p}=0.3)$.

\section{Costs}

An estimated saving of 35070 Euros was achieved through the decrease of hospitalisations for flare. After introduction of IBD education programme the number of hospitalisations for a flare was reduced ( 56 before vs 28 after; $\mathrm{p}=0.002$ ), and the number of days patients spent in hospital declined (375 days before with an estimated cost of $€ 264638,243$ days after with an estimated cost of $€ 229568)$.

\section{DISCUSSION}

The real difference observed was the decrease of onethird of the hospitalisations for flare. Moreover, emergency department visits could also be avoided, as there were no more visits despite the increase of patients followed up for IBD in our centre $(p=0.08)$. The cohort considered was uniformly diagnosed and uniformly treated: no newer biological therapies were introduced in the interval that could explain a lower hospitalisation ratio. The IBD team was also quite stable, and this also guaranteed higher quality of care. This difference can be attributed to the IBD nurse and IBD team work. Patients were better informed. They could have access to immediate information and join easily the IBD team through the IBD nurse in case of flare. As she provided immediate advice, she facilitated the access to the IBD team via telephone or email and rapid access in the event of a flare-up.

The positive effect and value of dedicated IBD nurses on outcomes were also shown by others. ${ }^{5-7}{ }^{10}$ Our data correspond to the results published recently by Leach $e t$ $a l^{11}$ and Coenen $e t a l,{ }^{10}$ showing that IBD nurses provide sustained direct cost reductions to healthcare by reducing hospital attendance.

Moreover, an estimated saving of $€ 35070$ was achieved through the decrease of hospitalisations for flare, as already shown by others. ${ }^{1011}$

Another significant difference was the $168 \%$ increase of hospitalisations for initial diagnosis and therefore the increase of patients followed up for IBD in our centre $(+24 \%)$. In the last decade, a dramatic increase in incidences of both $\mathrm{CD}$ and $\mathrm{UC}$ was observed in adolescents. ${ }^{13}$ However, the increase in the hospitalisations for diagnosis that we observed cannot be explained only by epidemiology. The introduction of the education programme for patients with IBD formalised the centre as an IBD centre with a higher level of visibility and thus a better recruitment.
Moreover, decreasing the number of hospitalisations for flare freed up space for new patients.

Of patients with IBD, $78.5 \%$ were included in the therapeutic patient education programme; only 29 patients that were expected did not fulfil their appointment. Our IBD nurse was able to support patients throughout the diagnosis, allowed rapid access to healthcare and empowered the patients to live as well as possible with their IBD. Our IBD nurse was therefore trained with a special IBD education programme; she followed also an IBD physician to catalyse the transference of experience. The levels of experience of the nurse who participated within the N-ECCO survey were similar: $38 \%$ having $1-5$ years of experience ${ }^{14}$; moreover, the N-ECCO survey of IBD nursing practice confirmed the wide variety of roles, responsibilities and level of autonomy IBD nurses hold across Europe. ${ }^{14}$

Another interesting fact is the reorganisation of the IBD team. A psychologist and a dietician joined the team. For the groups, a specialist pain team and the adapted physical activity professor were present for the group related to sport, fatigue and pain. Thirty-nine meetings gathered the team to share concerns about the patients and to improve the IBD healthcare system in the department: information brochures and booklets were designed, but also education materials (board games created for younger patients to allow them to understand their IBD). Moreover, the entire diagnosis announcement pathway was redesigned to ensure a better integration. All this strengthened the IBD team.

The major limitation was that costs were only attributed to the reduction of hospitalisation. This is a retrospective study: it may also impact biases to the reporting of data. With a prospective study, we could have analysed the number of calls to the IBD nurse, and therefore, we could really relate the role of the nurse to the reduction of hospitalisations.

This study suggests that introducing an IBD nurse position in a tertiary centre changes the lines, reinforces the IBD team and thus reduces hospital admissions. Instead of the traditional model, the IBD nurse provides accessible advice and allows the patients to be outpatients. So the key point now is how we can fund an IBD nurse in an IBD team, as we demonstrated how critical she is. Clinicians should become more business savvy and incisive about payment systems and funding models to offer to their patients just what they deserve. ${ }^{15}$

Contributors SL, JV, J-PH and CM-V worked on the conception and design of the project. $S L, A B, M L$ and $C M-V$ were involved in data acquisition and statistical analyses. CM-V was guarantor of the article. All authors contributed to interpretation of results and writing and approved the final version of the manuscript.

Funding The authors have not declared a specific grant for this research from any funding agency in the public, commercial or not-for-profit sectors.

Competing interests $\mathrm{CM}-\mathrm{V}$ received honoraria, speaker's fees and/or congress fees from AbbVie, MSD, Nestle and Biogen. J-PH received congress fees from MSD and Biogen.

Patient and public involvement Patients and/or the public were not involved in the design, conduct, reporting or dissemination plans of this research. 
Patient consent for publication Not required.

Ethics approval The study was approved by the Groupe Francophone d'HépatoGastroentérologie et Nutrition Pédiatriques Ethics Committee and the French National Data Protection Agency (Commission Nationale de l'Informatique et des Libertés (CNIL)). The CEMARA system benefits from an agreement with the CNIL

Provenance and peer review Not commissioned; externally peer reviewed.

Data availability statement Data are available upon reasonable request mailing to christine.martinez-vinson@aphp.fr. Data available: listing of educated patients and characteristics, listing of hospitalisations.

Open access This is an open access article distributed in accordance with the Creative Commons Attribution Non Commercial (CC BY-NC 4.0) license, which permits others to distribute, remix, adapt, build upon this work non-commercially, and license their derivative works on different terms, provided the original work is properly cited, appropriate credit is given, any changes made indicated, and the use is non-commercial. See: http://creativecommons.org/licenses/by-nc/4.0/.

\section{ORCID iD}

Christine Martinez-Vinson http://orcid.org/0000-0002-3010-6442

\section{REFERENCES}

1 Odes S, Vardi H, Friger M, et al. European collaborative study on inflammatory bowel disease. cost analysis and cost determinants in a European inflammatory bowel disease inception cohort with 10 years of follow-up evaluation. Gastroenterology 2006;131:719-28.

2 van Langenberg DR, Simon SB, Holtmann GJ, et al. The burden of inpatient costs in inflammatory bowel disease and opportunities to optimize care: a single metropolitan Australian center experience. $J$ Crohns Colitis 2010;4:413-21.

3 Sack C, Phan VA, Grafton R, et al. A chronic care model significantly decreases costs and healthcare utilisation in patients with inflammatory bowel disease. J Crohns Colitis 2012;6:302-10.
4 Kemp K, Dibley L, Chauhan U, et al. Second N-ECCO consensus statements on the European nursing roles in caring for patients with Crohn's disease or ulcerative colitis. $J$ Crohns Colitis 2018:12:760-76.

5 Nightingale AJ, Middleton W, Middleton SJ, et al. Evaluation of the effectiveness of a specialist nurse in the management of inflammatory bowel disease (IBD). Eur J Gastroenterol Hepatol 2000;12:967-73.

6 Smith GD, Watson R, Roger D, et al. Impact of a nurse-led counselling service on quality of life in patients with inflammatory bowel disease. J Adv Nurs 2002;38:152-60.

7 Jelsness-Jørgensen L-P, Bernklev T, Henriksen M, et al. Is patient reported outcome (pro) affected by different follow-up regimens in inflammatory bowel disease (IBD)? A one year prospective, longitudinal comparison of nurse-led versus conventional follow-up. $J$ Crohns Colitis 2012;6:887-94.

8 Belling R, McLaren S, Woods L. Specialist nursing interventions for inflammatory bowel disease. Cochrane Database Syst Rev 2009;4:CD006597.

9 Hernández-Sampelayo P, Seoane M, Oltra L, et al. Contribution of nurses to the quality of care in management of inflammatory bowel disease: a synthesis of the evidence. J Crohns Colitis 2010;4:611-22.

10 Coenen S, Weyts E, Vermeire S, et al. Effects of introduction of an inflammatory bowel disease nurse position on the quality of delivered care. Eur J Gastroenterol Hepatol 2017;29:646-50.

11 Leach P, De Silva M, Mountifield R, et al. The effect of an inflammatory bowel disease nurse position on service delivery. $J$ Crohns Colitis 2014:8:370-4.

12 Landais P, Messiaen C, Rath A, et al. CEMARA an information system for rare diseases. Stud Health Technol Inform 2010;160:481-5.

13 Ghione S, Sarter H, Fumery M, et al. Dramatic increase in incidence of ulcerative colitis and Crohn's disease (1988-2011): a population-based study of French adolescents. Am J Gastroenterol 2018;113:265-72.

14 O'Connor M, Gaarenstroom J, Kemp K, et al. N-ECCO survey results of nursing practice in caring for patients with Crohn's disease or ulcerative colitis in Europe. J Crohns Colitis 2014;8:1300-7.

15 Andrews JM. How to fund IBD nurses. J Gastroenterol Hepatol 2016;31 Suppl 1:43. 